\title{
Spectrum of ALDH1 mRNA in smokers and non-smokers with adenocarcinoma or squamous cell lung carcinoma
}

\author{
Da-Hua Liu, Fei-Fei Mou², Fu Ren¹, Pu Xia ${ }^{1,3}$
}

${ }^{1}$ Biological Anthropology Institute, Liaoning Medical University, Jinzhou, Liaoning, China
2Shijiazhuang Medical College, Shijiazhuang, Hebei, China
${ }^{3}$ Department of Cell Biology, College of Basic Medical Science, Liaoning Medical
University, Jinzhou, Liaoning, China

Submitted: 4 October 2018

Accepted: 15 December 2018

Arch Med Sci 2020; 16 (3): 709-713

DOI: https://doi.org/10.5114/aoms.2019.81310

Copyright (c) 2019 Termedia \& Banach

\section{Introduction}

Lung cancer is the leading cause of cancer-related death worldwide [1]. Non-small cell lung carcinoma (NSCLC) includes two main types: lung squamous cell carcinoma (LUSC) and lung adenocarcinoma (LUAD) [2]. Although many factors can affect the occurrence and development of lung cancer [3, 4], we all know the basic fact that smoking causes lung cancer. A comprehensive molecular profile is needed to elucidate tumorigenesis of smokers and non-smokers with lung cancer.

The ALDH1 family of enzymes (namely ALDH1A1, ALDH1A2 and ALDH1A3) is a cytosolic detoxifying enzyme responsible for the oxidation of (retin)aldehydes into retinoids [5]. It has been widely used to isolate cancer stem cells [6]. ALDH1 is involved in cell proliferation, differentiation, and drug resistance [7]. Ginestier et al. [8] found that ALDH1A1 expression detected by immunostaining correlated with poorer breast cancer patient prognosis. However, Neumeister et al. [9] found that ALDH1A1 expression alone does not significantly predict the therapeutic outcome of breast cancer patients. So, it is hard for a single study to assess the robustness of the relationship between ALDH1A1 expression and the clinicopathologic parameters of cancer patients. The objective of this project is to explore the impact of tobacco consumption and histology type on ALDH1 expression.

\section{Material and methods}

\section{Oncomine database analysis}

The mRNA levels of ALDH1A1, ALDH1A2 and ALDH1A3 in lung cancer tissues were compared with their matched normal tissues by using TCGA datasets in the Oncomine database (http://www.oncomine.org). The threshold used to obtain the most significant probes of the queried gene for each microarray data included a two-fold difference in expression between cancers and normal tissues with a $p$-value $<1 \times 10^{-4}$.

\section{Kaplan-Meier plotter analysis}

The prognostic value of ALDH1A1, ALDH1A2 and ALDH1A3 in lung cancer was analyzed using the Kaplan-Meier (KM) plotter (http://kmplot.com/ analysis/). Overall survival of patients with high and low levels of ALDH1A1,

\author{
Corresponding authors: \\ Ren Fu PhD \\ Biological Anthropology \\ Institute \\ Liaoning Medical University \\ Jinzhou, Liaoning, China \\ E-mail: rf@jzmu.edu.cn \\ Pu Xia PhD \\ Department \\ of Cell Biology \\ College of Basic \\ Medical Science \\ Biological Anthropology \\ Institute \\ Liaoning Medical University \\ Jinzhou 121001, China \\ E-mail: nn001007@163.com
}



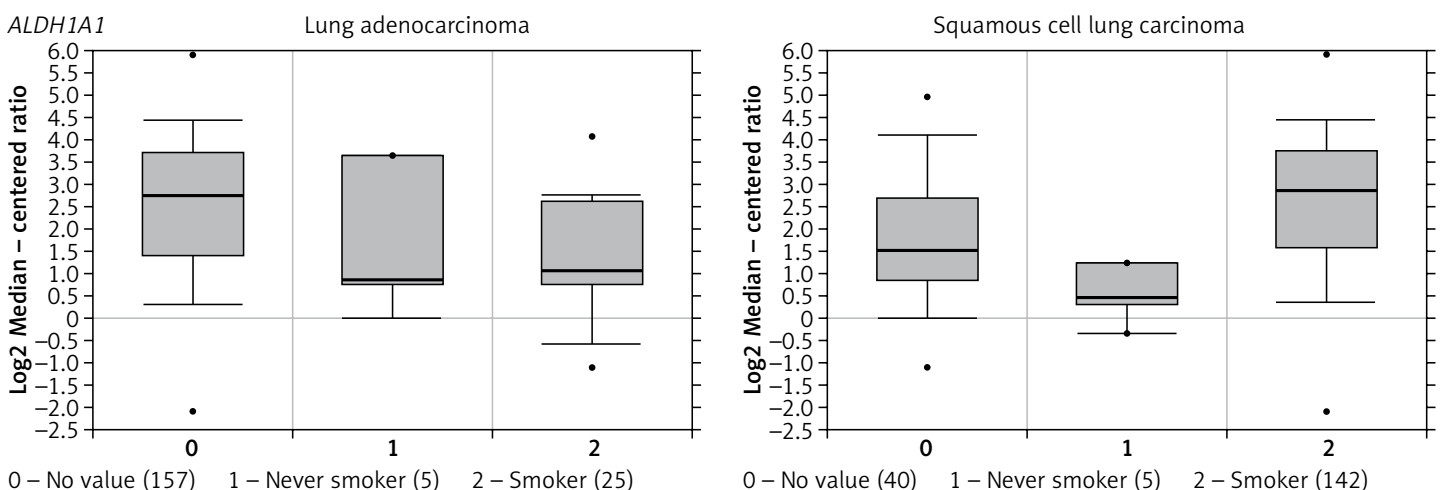

ALDH1A1

Lung adenocarcinoma

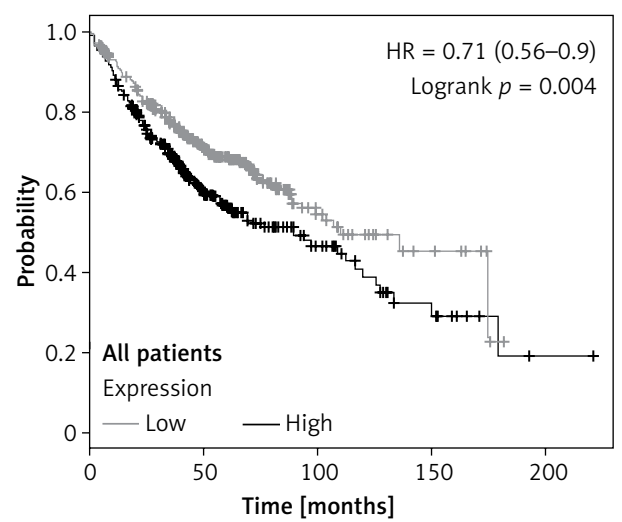

Number at risk:

$\begin{array}{llllcl}\text { Low } & 360 & 152 & 31 & 10 & 1 \\ \text { High } & 360 & 196 & 38 & 9 & 0\end{array}$

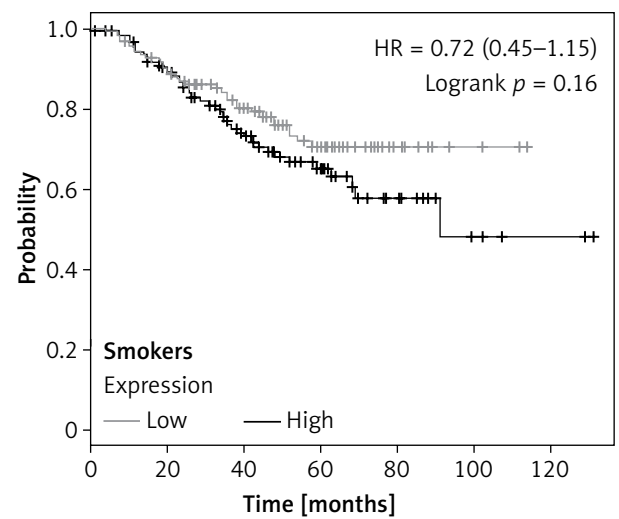

Number at risk:

$\begin{array}{lccccccc}\text { Low } & 123 & 103 & 68 & 41 & 12 & 4 & 2\end{array}$

High $\quad \begin{array}{lllllll}123 & 109 & 80 & 48 & 11 & 3 & 0\end{array}$

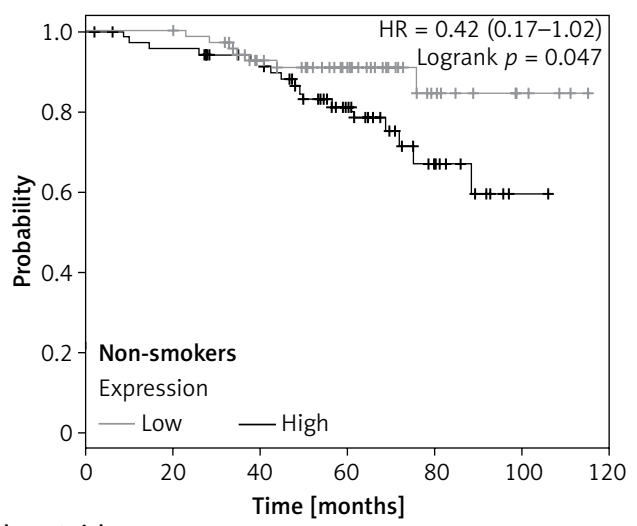

Squamous cell lung carcinoma

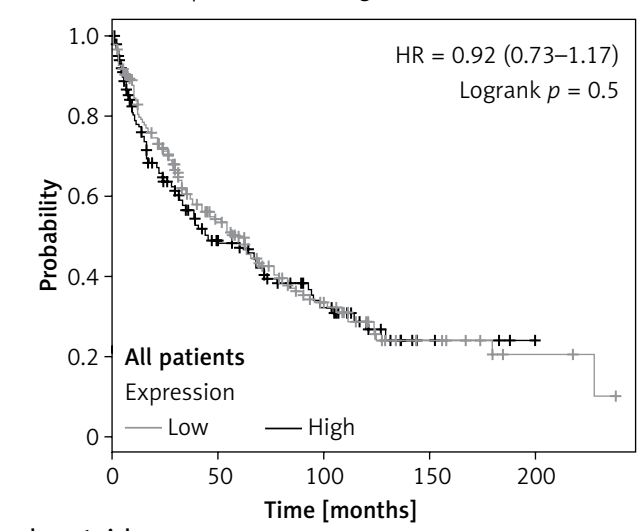

Number at risk:

$\begin{array}{llcccc}\text { Low } & 262 & 75 & 22 & 4 & 1 \\ \text { High } & 262 & 104 & 32 & 11 & 3\end{array}$

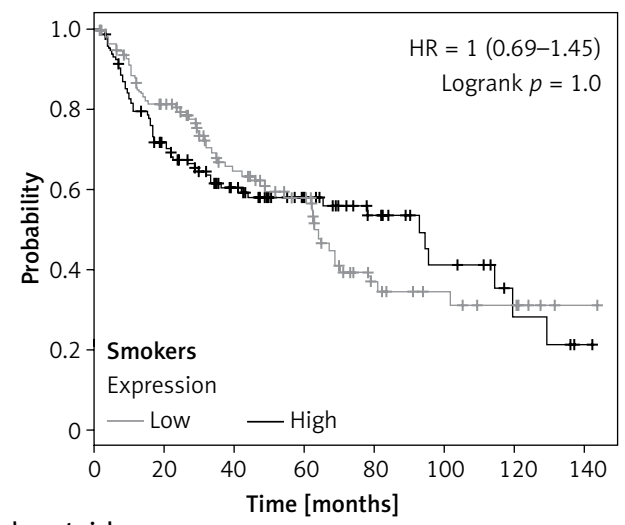

Number at risk:

$\begin{array}{lllllllll}\text { Low } & 122 & 81 & 52 & 35 & 20 & 10 & 4 & 1 \\ \text { High } & 122 & 90 & 56 & 39 & 15 & 10 & 7 & 1\end{array}$

Number at risk

Time [months]

Figure 1. ALDH1A1 mRNA was evaluated in both smokers and non-smokers with LUSC or LUAD using Oncomine analysis. Univariate Kaplan-Meier survival analysis of ALDH1A1 in both smokers and non-smokers with LUSC or LUAD was performed using datasets compiled with KM plotter 

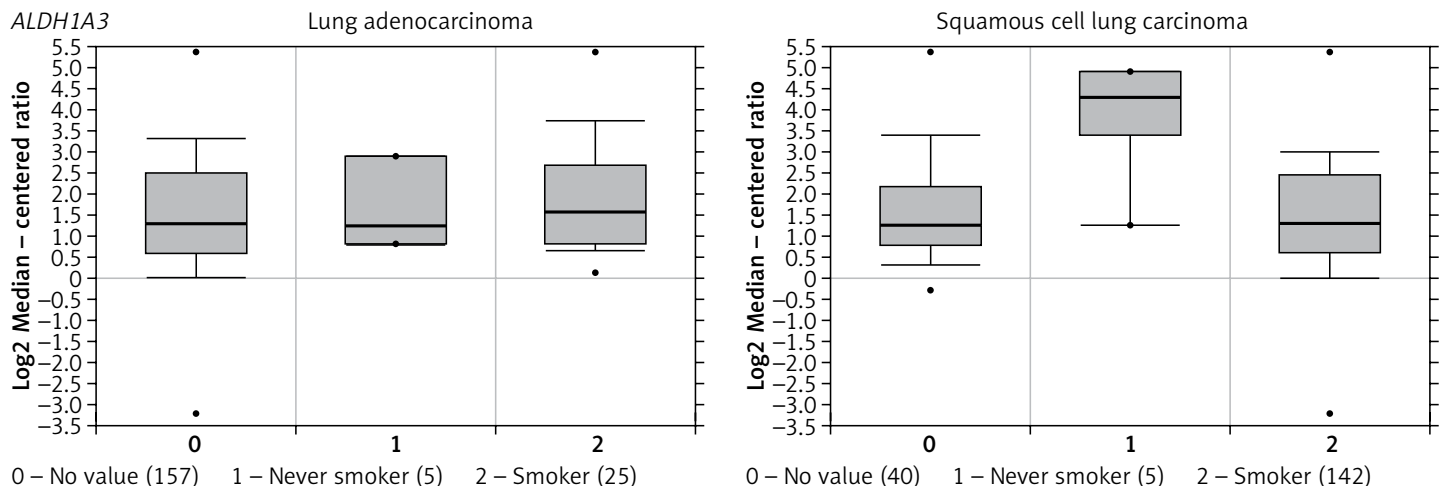

ALDH1A3

Lung adenocarcinoma

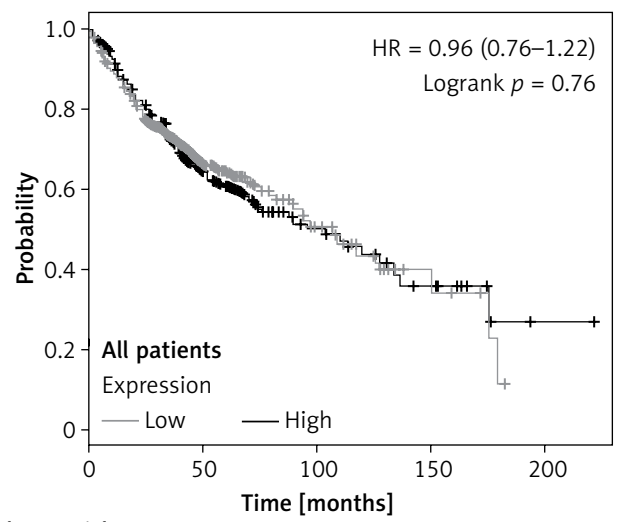

Number at risk:

$\begin{array}{lccccc}\text { Low } & 360 & 171 & 41 & 12 & 1 \\ \text { High } & 360 & 177 & 28 & 7 & 0\end{array}$

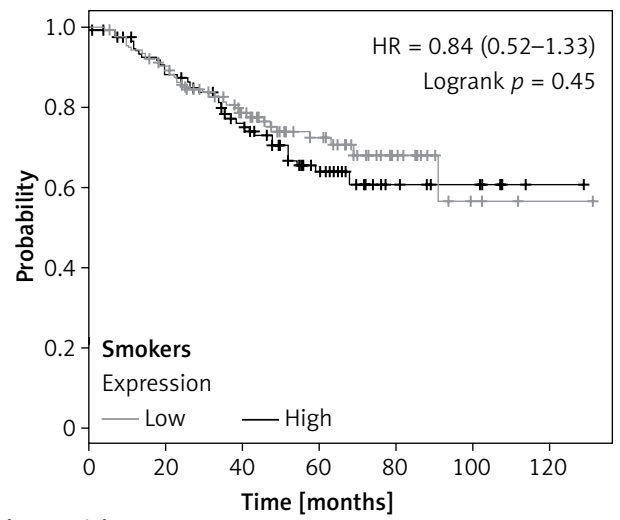

$\begin{array}{lccccc}\text { Number at risk: } & & & \\ \text { Low } & 262 & 93 & 23 & 7 & 2 \\ \text { High } & 262 & 86 & 31 & 8 & 2\end{array}$
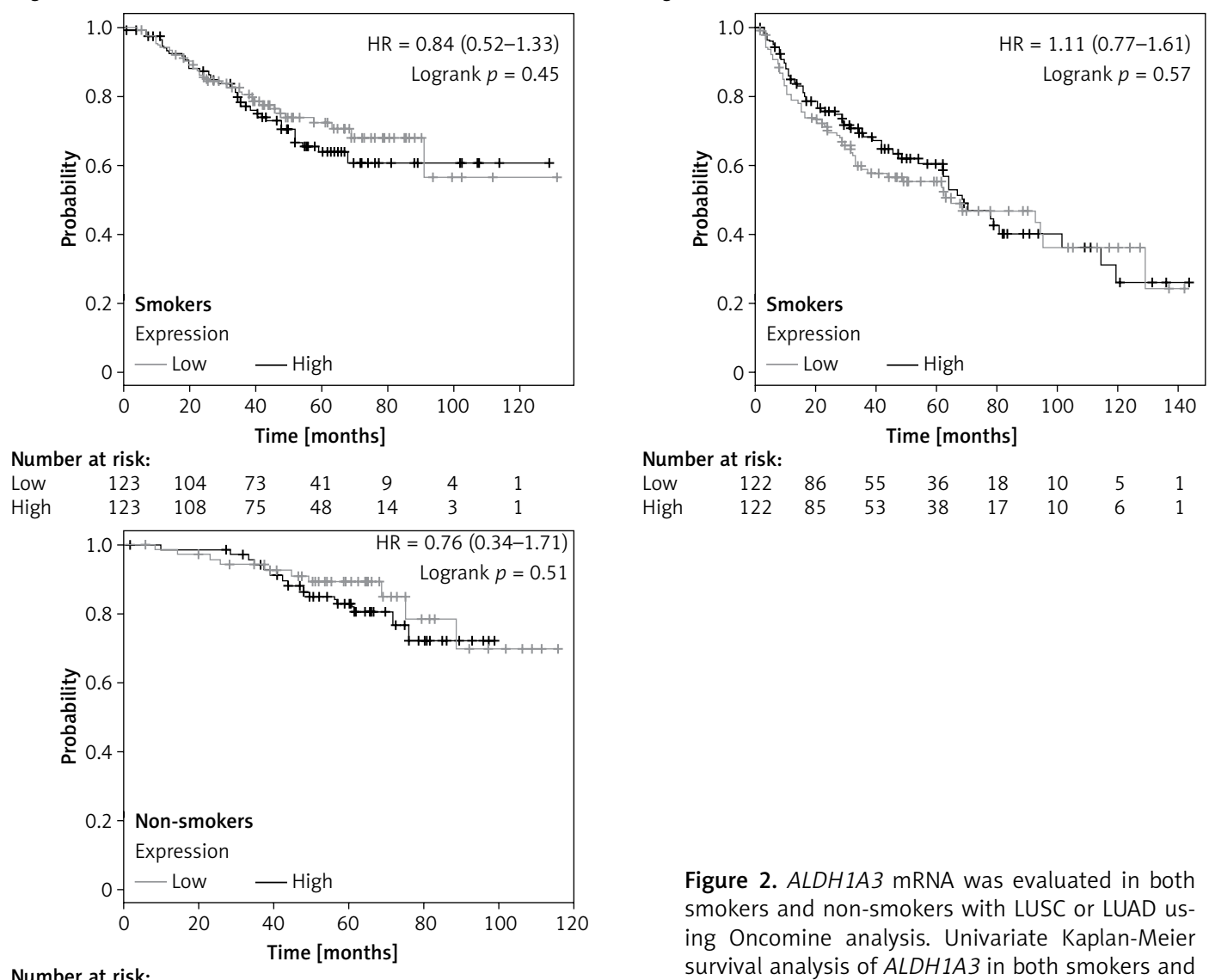

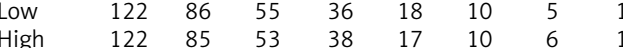

Number at risk:

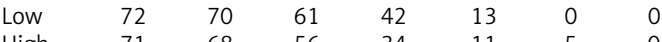

Figure 2. ALDH1A3 mRNA was evaluated in both smokers and non-smokers with LUSC or LUAD using Oncomine analysis. Univariate Kaplan-Meier survival analysis of $A L D H 1 A 3$ in both smokers and non-smokers with LUSC or LUAD was performed using datasets compiled with KM plotter 


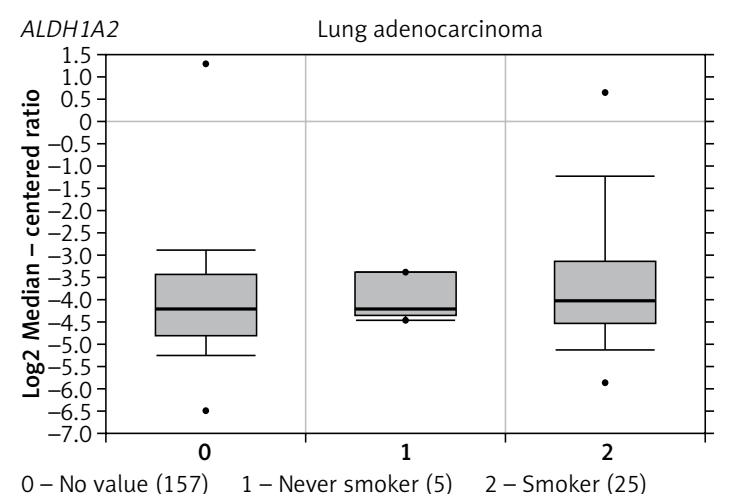

0 - No value (157) 1 - Never smoker (5) 2-Smoker (25)

ALDH1A2

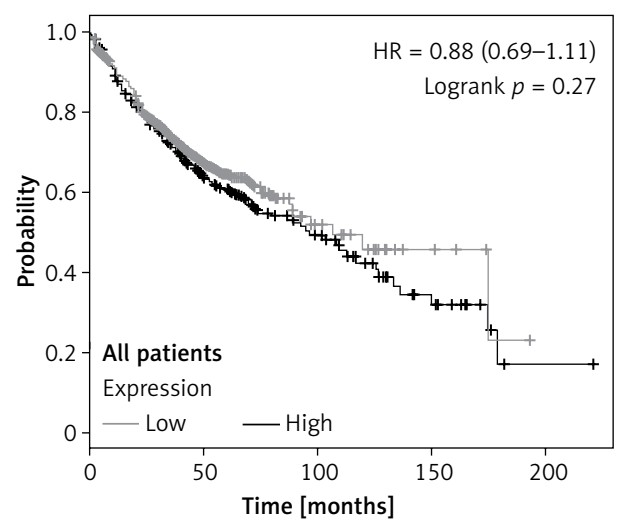

Number at risk:

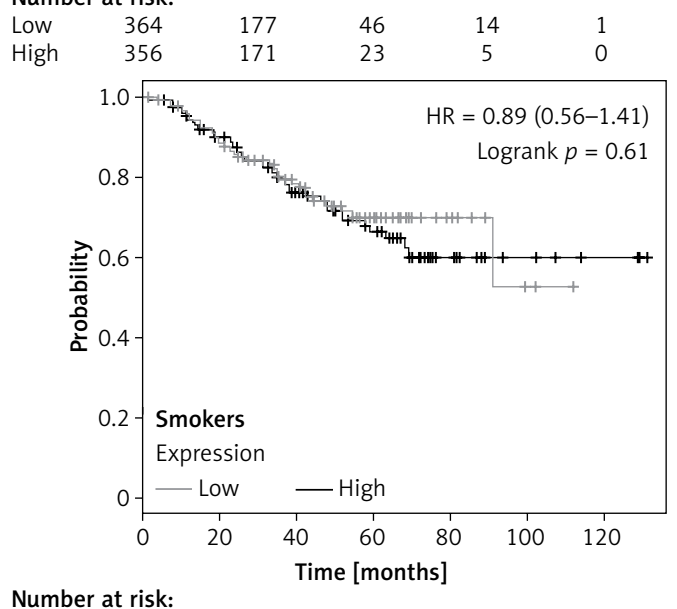

Number at risk:

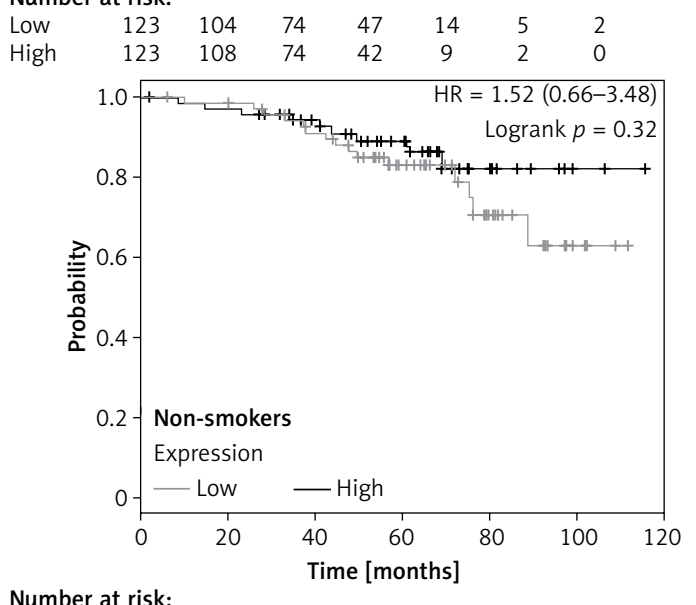

$\begin{array}{llllllll}\text { Low } & 72 & 69 & 57 & 42 & 11 & 2 & 0 \\ \text { High } & 71 & 69 & 60 & 34 & 13 & 3 & 0\end{array}$

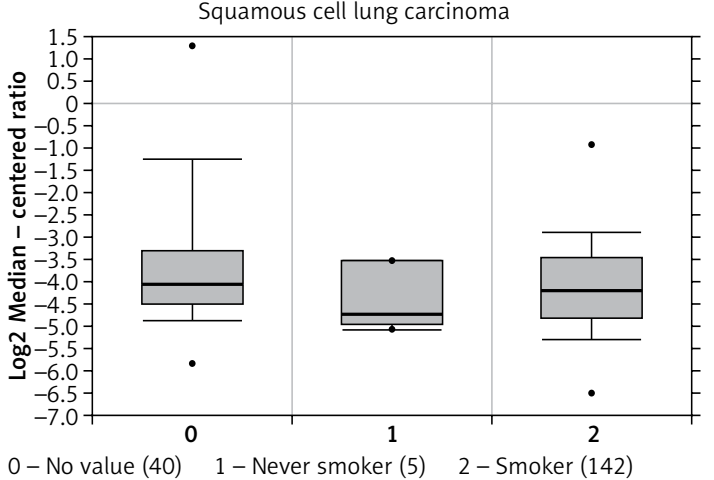

0 - No value (40) 1 - Never smoker (5) 2-Smoker (142)

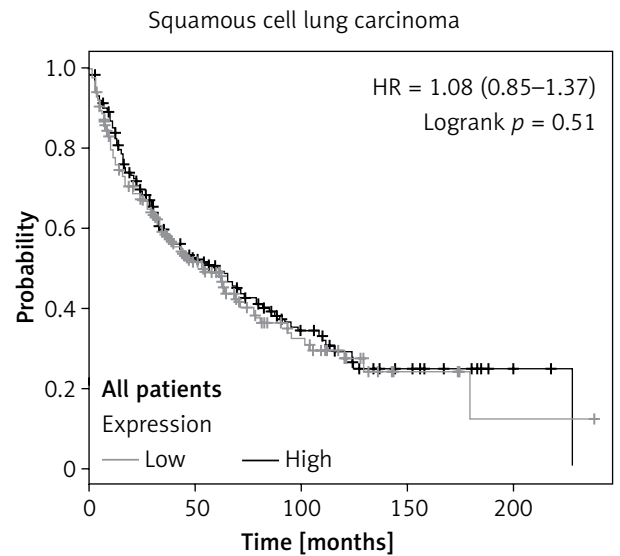

Number at risk:

$\begin{array}{llllcl}\text { Low } & 262 & 96 & 31 & 12 & 3 \\ \text { High } & 262 & 83 & 23 & 3 & 1\end{array}$

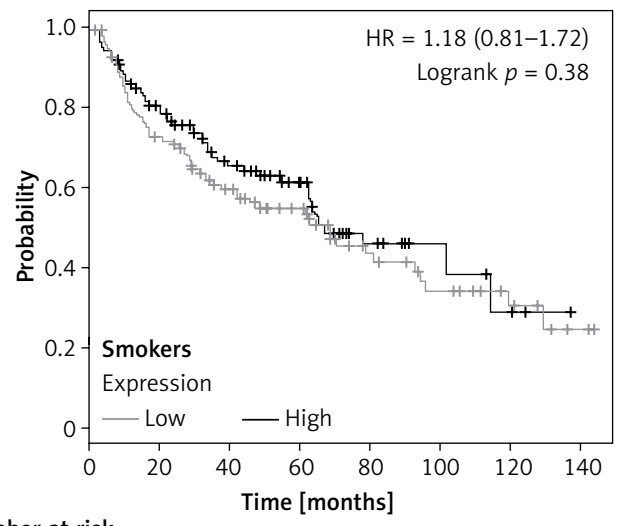

Number at risk:

$\begin{array}{lllllllll}\text { Low } & 122 & 87 & 54 & 34 & 14 & 6 & 3 & 0 \\ \text { High } & 122 & 84 & 54 & 40 & 21 & 14 & 8 & 2\end{array}$

Figure 3. ALDH1A2 mRNA was evaluated in both smokers and non-smokers with LUSC or LUAD using Oncomine analysis. Univariate Kaplan-Meier survival analysis of ALDH1A2 in both smokers and non-smokers with LUSC or LUAD was performed using datasets compiled with KM plotter 
ALDH1A2 and ALDH1A3 was shown using a Kaplan-Meier survival plot.

\section{Results}

\section{ALDH1A1, ALDH1A2 and ALDH1A3 in LUSC and LUAD tissues}

Based on the Oncomine analysis of cancer vs. normal tissue, we found that ALDH1A1 mRNA was significantly higher in the LUSC tissues of smokers than that in non-smokers (Figure 1). ALDH1A3 mRNA was significantly lower in the LUSC tissues of smokers than that in non-smokers (Figure 2). No significant difference of ALDH1A2 mRNA was found in LUSC tissues of smokers and non-smokers (Figure 3). ALDH1A1, ALDH1A2 and ALDH1A3 showed no significant difference in LUAD tissues of smokers and non-smokers (Figures 1-3). Kaplan-Meier analysis revealed that high ALDH1A1 mRNA was correlated with a benign survival rate of non-smokers with LUAD ( $p=0.047$, Figure 1). No influence of ALDH1A2 and ALDH1A3 mRNA was found in either smokers or non-smokers with LUSC or LUAD ( $p>0.05$, Figures 1-3).

\section{Discussion}

In this brief report, we used bioinformatics analysis to describe the mRNA levels of ALDH1 family members (ALDH1A-3) in LUSC and LUAD tissues. In the study of Patel et al., they found higher expression of ALDH1A1 in lung specimens from smokers when compared to non-smokers [10]. Consistent with their study, a higher ALDH1A1 mRNA level was found in the LUSC tissues of smoker in this study. Cigarette smoking seems to be an inducer of ALDH1A1. You et al. [11] found that ALDH1A1 mRNA in NSCLC is associated with better prognosis. In this study, we found that high ALDH1A1 mRNA was correlated with a benign survival rate of non-smokers with LUAD using the KM plotter. In most cancers, high expression of the ALDH1A1 protein was associated with a poor prognosis, such as breast cancer [12], colorectal carcinoma [13], and gastric cancer [14]. In a meta-analysis, ALDH1 was an independent factor associated with reduced survival of lung cancer patients [13]. Based on the present data, we cannot conclude the reason for the discordance between ALDH1A1 protein and mRNA [15].

In conclusion, our results showed that $A L D$ H1A1 mRNA could be used as a favorable marker of non-smokers with LUAD. This marker should be further evaluated for its potential use in tracking lung cancer stem cells in vivo and in vitro.

\section{Acknowledgments}

This study was supported by the National Natural Scientific Foundation of China (81502558), the President Fund of Liaoning Medical University (XZJJ20140102), and the Biological Anthropology Innovation Team Project of JZMU (JYLJ201702).

\section{Conflict of interest}

The authors declare no conflict of interest.

\section{References}

1. Siegel RL, Miller KD, Jemal A. Cancer statistics, 2016. CA Cancer J Clin 2016; 66: 7-30.

2. Shan S, She J, Xue ZQ, Su CX, Ren SX, Wu FY. Clinical characteristics and survival of lung cancer patients associated with multiple primary malignancies. PLoS One 2017; 12: e0185485.

3. Wang W, Song Z, Zhang Y. Efficacy of brain radiotherapy plus EGFR-TKI for EGFR-mutated non-small cell lung cancer patients who develop brain metastasis. Arch Med Sci 2018; 14: 1298-307.

4. Liu HN, Qie P, Yang G, Song YB. miR-181b inhibits chemoresistance in cisplatin-resistant $\mathrm{H} 446$ small cell lung cancer cells by targeting Bcl-2. Arch Med Sci 2018; 14: 745-51.

5. Zhou L, Yu L, Zhu B, et al. Metastasis-associated in colon cancer-1 and aldehyde dehydrogenase 1 are metastatic and prognostic biomarker for non-small cell lung cancer. BMC Cancer 2016; 16: 876.

6. Roudi R, Korourian A, Shariftabrizi A, Madjd Z. Differential expression of cancer stem cell markers ALDH1 and CD133 in various lung cancer subtypes. Cancer Invest 2015; 33: 294-302.

7. Nishikawa S, Konno M, Hamabe A, et al. Aldehyde dehydrogenase high gastric cancer stem cells are resistant to chemotherapy. Int J Oncol 2013; 42: 1437-42.

8. Ginestier C, Hur MH, Charafe-Jauffret E, et al. ALDH1 is a marker of normal and malignant human mammary stem cells and a predictor of poor clinical outcome. Cell Stem Cell 2017; 1: 555-67.

9. Neumeister V, Agarwal S, Bordeaux J, Camp RL, Rimm DL. In situ identification of putative cancer stem cells by multiplexing ALDH1, CD44, and cytokeratin identifies breast cancer patients with poor prognosis. Am J Pathol 2010; 176: 2131-8.

10. Patel M, Lu L, Zander DS, Sreerama L, Coco D, Moreb JS. ALDH1A1 and ALDH3A1 expression in lung cancers: correlation with histologic type and potential precursors. Lung Cancer 2008; 59: 340-9.

11. You Q, Guo H, Xu D. Distinct prognostic values and potential drug targets of ALDH1 isoenzymes in non-smallcell lung cancer. Drug Des Devel Ther 2015; 9: 5087-97.

12. Mieog JS, de Kruijf EM, Bastiaannet E, et al. Age determines the prognostic role of the cancer stem cell marker aldehyde dehydrogenase-1 in breast cancer. BMC Cancer 2012; 12: 42.

13. Xu SL, Zeng DZ, Dong WG, et al. Distinct patterns of ALDH1A1 expression predict metastasis and poor outcome of colorectal carcinoma. Int J Clin Exp Pathol 2014; 7: 2976-86.

14. Li XS, Xu Q, Fu XY, Luo WS. ALDH1A1 overexpression is associated with the progression and prognosis in gastric cancer. BMC Cancer 2014; 14: 705.

15. Huo W, Du M, Pan X, Zhu X, Li Z. Prognostic value of ALDH1 expression in lung cancer: a meta-analysis. Int J Clin Exp Med 2015; 8: 2045-51. 